\title{
Laryngopharyngeal Reflux: Is It the Real Culprit in Patients with Laryngeal Complaints?
}

\author{
${ }^{1}$ Ruta V Shah, ${ }^{2}$ Rajesh Vishwakarma
}

\begin{abstract}
Aim: The aim of this study is to evaluate the role of laryngopharyngeal reflux (LPR) in patients with laryngeal complaints and study the correlation between reflux symptom index (RSI) and reflux finding score (RFS).
\end{abstract}

Materials and methods: This is a study of 104 patients, who presented in the ear, nose, and throat outpatient department at the Civil Hospital, Ahmedabad, India, from April 2015 to April 2016, with complaints like change of voice, chronic cough, foreign body sensation, throat clearing, difficulty swallowing, and regurgitation.

All the patients were examined with $90^{\circ}$ endoscope by a single examiner, and an $\mathrm{RSI} \geq 13$ was considered as indicative of reflux.

Observation and discussion: The mean age of the 104 patients was 47.2 years. The male-female ratio was $1: 1.8$. The $\mathrm{RSI}$ ranged from 5 to 44 , with a mean of 22.99 and standard deviation (SD) of 7.43. The RFS ranged from 4 to 22 , with a mean of 11.04 and SD of 3.07. Both the parameters showed high correlation (correlation coefficient 0.98).

Conclusion: The LPR plays an important contributory role in patients with laryngeal complaints. The RFS and RSI can be used as routine parameters in establishing the diagnosis of reflux.

Keywords: Laryngopharyngeal reflux, Reflux finding score, Reflux symptom index.

How to cite this article: Shah RV, Vishwakarma R. Laryngopharyngeal Reflux: Is It the Real Culprit in Patients with Laryngeal Complaints? Int J Phonosurg Laryngol 2017; $7(1): 6-9$.

Source of support: Nil

Conflict of interest: None

\section{INTRODUCTION}

The laryngopharyngeal reflux is defined as the reflux of gastric contents into the larynx and pharynx (Vakil et al). ${ }^{1}$ The LPR may be manifested as laryngeal symptoms,

\footnotetext{
${ }^{1}$ Assistant Professor, ${ }^{2}$ Professor and Head

${ }^{1}$ Department of ENT, Sushilaben Mansukhlal Shah Multispeciality Hospital, Ahmedabad, Gujarat, India

${ }^{2}$ Department of ENT, Civil Hospital, B.J. Medical College Ahmedabad, Gujarat, India

Corresponding Author: Ruta V Shah, Assistant Professor Department of ENT, Sushilaben Mansukhlal Shah Multispeciality Hospital, Ahmedabad, Gujarat, India, Phone: +917926403938, e-mail: ruta.sayani@gmail.com
}

such as cough, sore throat, hoarseness, dysphonia, and globus, as well as signs of laryngeal irritation at laryngoscopy. ${ }^{2}$

In 1979, Pellegrini et $\mathrm{al}^{3}$ were the first to document links between airway symptoms and reflux of gastric contents. They also proved that treatment of reflux disease results in elimination of these airway symptoms.

The LPR is a term used since 1996 by Koufman et al ${ }^{4}$ to designate symptoms, signs, or tissue damage resulting from the return of gastroduodenal contents into the upper aerodigestive tract.

In recent years, it has become apparent that stomach acid is only a part of the equation. Research suggests that the stomach enzyme pepsin plays a crucial role in the complex mechanism behind LPR. ${ }^{5,6}$

Laryngopharyngeal symptoms can lead to symptoms, such as dry cough, throat clearing, posterior discharge, dysphonia, difficulty swallowing solids or liquids or episodes of asphyxia, heartburn, or regurgitation. So, it is important for the ear, nose, and throat (ENT) specialists to identify the signs and symptoms of LPR and treat them accordingly.

\section{MATERIALS AND METHODS}

This is a study of 111 patients who presented to the ENT outpatient department at the Civil Hospital Ahmedabad, India, from April 2015 to April 2016 with laryngeal complaints like change of voice, cough, difficulty swallowing, foreign body sensation, throat clearing, regurgitation, etc. After 7 patients (4-laryngeal malignancy, 3-vocal cord palsy) were excluded from the study, the remaining 104 patients were evaluated with $90^{\circ}$ endoscope by a single examiner after spraying the throat with LOX $10 \%$ spray.

We used the symptom questionnaire and classification proposed by Belafsky et $\mathrm{al}^{7}$ to grade the signs and symptoms of LPR.

\section{Reflux Symptom Index}

A score $\geq 13$ was taken to be suggestive of reflux (Table 1).

\section{Reflux Finding Score}

The reflux finding score $\geq 7$ is suggestive of LPR (Table 2). 
Table 1: Reflux symptom index: During the last month how did the following problems affect you?

\begin{tabular}{|c|c|c|c|c|c|c|}
\hline Hoarseness or a problem with your voice & 0 & 1 & 2 & 3 & 4 & 5 \\
\hline Clearing your throat & 0 & 1 & 2 & 3 & 4 & 5 \\
\hline Excess throat mucus or postnasal drip & 0 & 1 & 2 & 3 & 4 & 5 \\
\hline Difficulty swallowing food, liquids, or pills & 0 & 1 & 2 & 3 & 4 & 5 \\
\hline Coughing after you ate or after lying down & 0 & 1 & 2 & 3 & 4 & 5 \\
\hline Difficulty breathing or choking episodes & 0 & 1 & 2 & 3 & 4 & 5 \\
\hline Troublesome or annoying cough & 0 & 1 & 2 & 3 & 4 & 5 \\
\hline Sensation of something sticking in your throat/lump in throat & 0 & 1 & 2 & 3 & 4 & 5 \\
\hline Heartburn, chest pain, indigestion, or stomach acid coming up & 0 & 1 & 2 & 3 & 4 & 5 \\
\hline
\end{tabular}

0 = no problem, 5 = severe problem (adapted from Belafsky PC, Postma GN, Koufman JA. Validity and reliability of the reflux symptom index. J Voice 2002).

Table 2: Reflux finding score

\begin{tabular}{ll}
\hline Subglottic edema & $0=$ absent \\
& $2=$ present \\
& $2=$ partial \\
Ventricular obliteration & $4=$ complete \\
& $2=$ Arytenoids only \\
Erythema/hyperemia & $4=$ diffuse \\
Vocal fold edema & $1=$ mild \\
& $2=$ moderate \\
& $3=$ severe \\
& $4=$ polypoid \\
& $1=$ mild \\
Diffuse laryngeal edema & $2=$ moderate \\
& $3=$ severe \\
& $4=$ obstructing \\
& $1=$ mild \\
Posterior commissure hypertrophy & $2=$ moderate \\
& $3=$ severe \\
& $4=$ obstructing \\
& $0=$ absent \\
2 & $=$ present \\
Granuloma/granulation & $0=$ absent \\
& $2=$ present \\
\hline
\end{tabular}

\section{OBSERVATION AND DISCUSSION}

\section{Age and Sex Distribution}

The age of the patients ranged from 17 to 81 years, with a mean of 47.2 years. Of the 104 patients, 67 were females and 37 were males. So, the female:male ratio was 1.8:1.

\section{Symptoms}

Predominant laryngeal complaints encountered in our study were cough and change of voice (Graph 1).

\section{Reflux Symptom Index}

Reflux symptom index ranged from 5 to 44 , with a mean of 22.99 and SD 7.43. The RSI $\geq 13$ is indicative of reflux. Only 4 of the 104 patients had RSI $<13$. The remaining 100 patients with laryngeal complaints had a score $\geq 13$, which was suggestive of LPR (Graph 2).

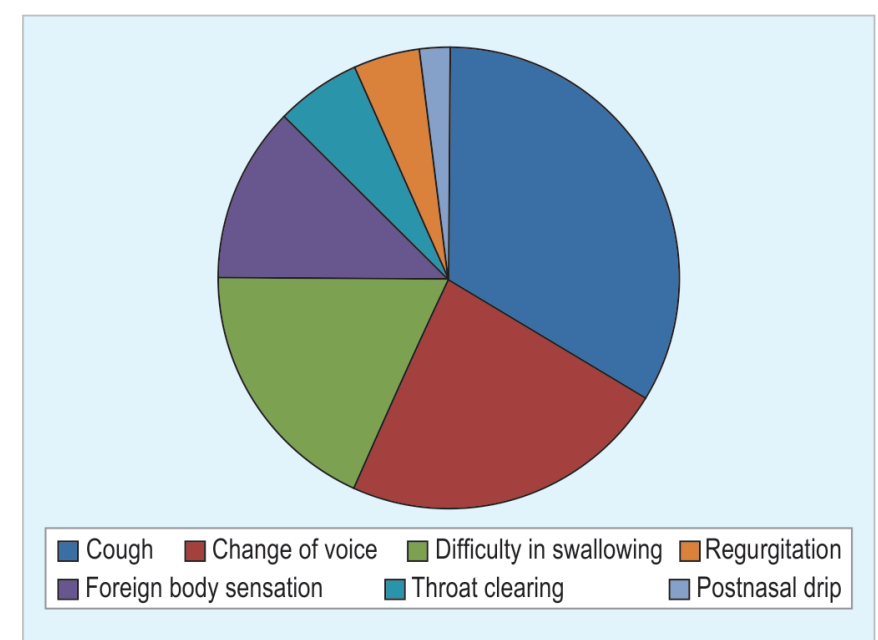

Graph 1: Symptom distribution in patients with laryngeal complaints. Symptoms: Predominant laryngeal complaints encountered in our study were cough and change of voice

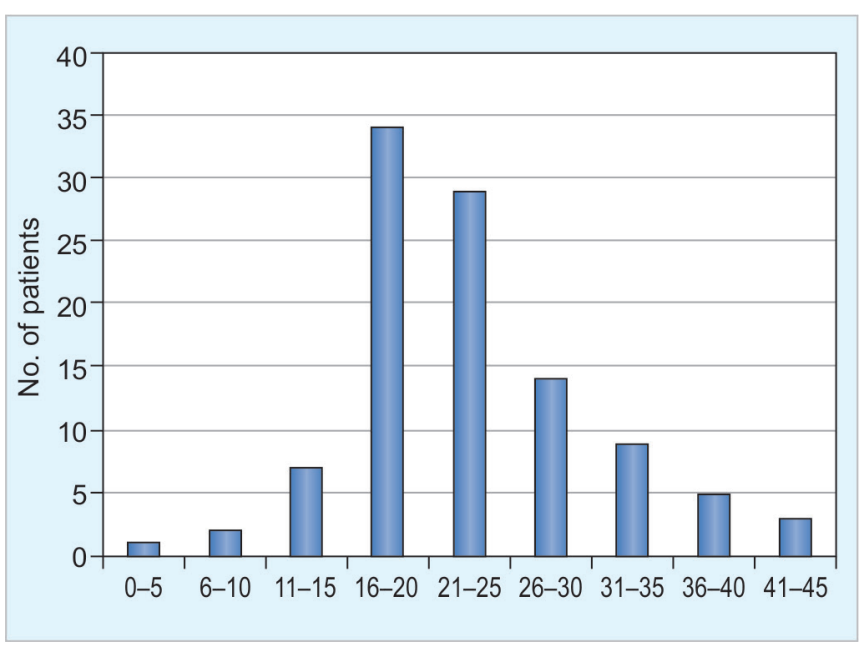

Graph 2: Reflux symptom index distribution

\section{Reflux Finding Score}

The RFS ranged from 4 to 22 , with a mean of 11.04 and SD 3.07. Only 5 patients with RSI $\geq 13$ had RFS $<7$. The most common findings on endoscopy of patients with LPR were arytenoids, hyperemia, and posterior commissure hypertrophy (Graph 3). 


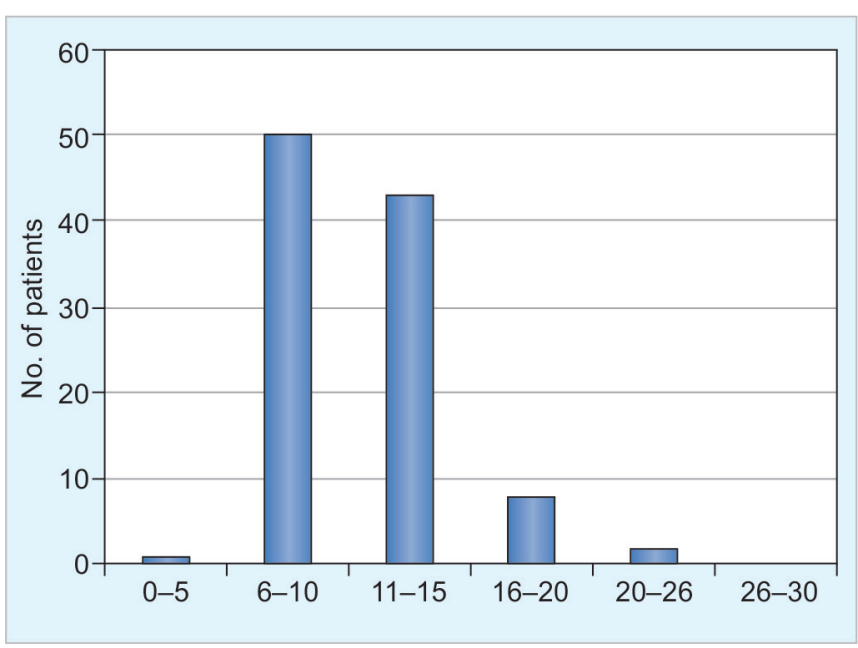

Graph 3: Reflux finding score distribution

\section{DISCUSSION}

The LPR refers to the retrograde flow of gastric contents to the upper aerodigestive tract. There are various physiological barriers to prevent LPR, such as the lower esophageal sphincter, esophageal clearance influenced by esophageal peristalsis, saliva and gravity, and the upper esophageal sphincter. When these barriers fail, stomach contents come in contact with the laryngopharyngeal tissue, causing damage to the epithelium, ciliary dysfunction, inflammation, and altered sensitivity. ${ }^{8}$ In our study of patients with laryngeal complaints, the mean age of patients with laryngeal complaints was 47.2 years. The male-female ratio was 1:1.8. The RSI and RFS had a correlation coefficient of 0.98 .

Various tests are available for diagnosing and documenting LPR. However, there remains wide divergence among specialists on the diagnosis of LPR.

\section{pH Monitoring}

Reflux events are best demonstrated by multichannel intraluminal impedence $\mathrm{pH}$ monitoring. This method can detect acid and nonacid or gaseous fluid. ${ }^{9}$ Multichannel intraluminal impedence $\mathrm{pH}$ monitoring is useful for the diagnosis of LPR, but the methods tested vary widely and there is no consensus regarding the definition of abnormal $\mathrm{pH} .{ }^{10}$ The process is also invasive and results are variable.

\section{Empirical Treatment}

In view of controversial diagnostic criteria for LPR, empirical treatment with proton pump inhibitors (PPIs) has been used as an alternative diagnostic modality in which a favorable response is defined as diagnostic confirmation. ${ }^{10,11}$

\section{Laryngoscopy}

The laryngoscopic findings used for the diagnosis of reflux are nonspecific signs of laryngeal irritation and inflammation. The laryngeal examination identifies edema and erythema, particularly in the posterior region as signs of LPR. However, the examination depends on the examiner; variations may exist that make the precise diagnosis of LPR highly subjective. ${ }^{12}$

In our study, RSI and RFS showed high correlation, and only 5 patients with RSI $\geq 13$ had RFS $<7$. Thus, RSI and RFS had significant correlation. They can be used as routine parameters in ENT examination to diagnose LPR.

\section{Treatment}

- Lifestyle modifications: Treatment of LPR consists of dietary changes and lifestyle changes like weight loss, restriction of smoking, alcohol, caffeine.

- Medical management: Drugs most commonly used to treat LPR are PPIs, which suppress acid production by directly acting on the $\mathrm{H}^{+}-\mathrm{K}^{+}$adenosine triphosphatase of parietal cells. The PPIs not only prevent exposure of the upper aerodigestive tract, but also reduce the damage resulting from the enzymatic activity of pepsin, which requires an acid medium for activation. ${ }^{13}$

Clinical evidence indicates that pharmacologic intervention should comprise a minimum of 3 months of treatment with PPIs administered twice a day, 30 to 60 minutes before a meal. In contrast to gastroesophageal reflux disease (GERD), the therapeutic response of patients with LPR to PPIs is variable, in part because LPR requires more aggressive and prolonged therapy than GERDD. ${ }^{14}$ Although most patients show improvement of symptoms within 3 months, the resolution of symptoms and laryngeal findings generally takes 6 months. ${ }^{15}$

- Surgical management: Laproscopic or Nissen fundoplication is a well-established surgical treatment for GERD and produces reliable and reproducible results. ${ }^{16} \mathrm{How}$ ever, its role in the management of LPR is uncertain. It has been suggested that Nissen fundoplication should not be performed in patients resistant to PPIs. ${ }^{2}$

\section{CONCLUSION}

The LPR is a clinical entity widely recognized by otorhinolaryngolists because of its various laryngeal manifestations. Various invasive/noninvasive, subjective/ objective tests have been used in its diagnosis with varied results. However, RSI and RFS have high correlation rates and can be included by ENT specialists for establishing the diagnosis of LPR and treat its laryngeal manifestations. 


\section{REFERENCES}

1. Vakil N, Van Zanten S, Kahrilas P, Dent J, Jones R. The Montreal definition and classification of gastroesophageal reflux disease: a global evidence-based consensus. Am J Gastroenterol 2006;101:1900-1920.

2. Vaezi MF, Hicks DM, Abelson TI, Richter JE. Laryngeal signs and symptoms and GERD: a critical assessment of cause and effect association. Clin Gastroenterol Hepatol 2003 Sep;1(5):333-344.

3. Pellegrini CA, DeMeester TR, Johnson LF, Skinner DB. Gastroesophageal reflux and results of surgical therapy. Surgery 1979 Jul;86(1):110-119.

4. Koufman J, Sataloff RT, Toohill R. Laryngopharyngeal reflux: consensus conference report. J Voice 1996 Sep;10(3):215-216.

5. Bardhan KD, Strugala V, Dettmar PW. Reflux revisited: advancing the role of pepsin. Int J Otolaryngol 2012;2012: 646901.

6. Expert-Interview: The crucial role of pepsin in LPR. Refluxgate 2016 Apr 9. Retrieved 2016 Jun 16.

7. Belafsky PC, Postma GN, Koufman JA. Validity and reliability of the reflux symptom index (RSI). J Voice 2002,274-277.

8. Campagnolo AM, Priston J, Thoen RH, Medeiros T, Assunção AR. Laryngopharyngeal reflux: diagnosis, treatment and latest research. Int Arch Otorhinolaryngol 2014 Apr;18(2): 184-191.

9. Noordzij JP, Khidr A, Desper E, Meek RB, Reibel JF, Levine PA. Correlation of $\mathrm{pH}$ probe-measured laryngopharyngeal reflux with symptoms and signs of reflux laryngitis. Laryngoscope 2002 Dec;112(12):2192-2195.

10. Abou-Ismail A, Vaezi MF. Evaluation of patients with suspected laryngopharyngeal reflux: a practical approach. Curr Gastroenterol Rep 2011 Jun;13(3):213-218.

11. Wood JM, Hussey DJ, Woods CM, Watson DI, Carney AS. Biomarkers and laryngopharyngeal reflux. J Laryngol Otol 2011 Dec;125(12):1218-1224.

12. Branski RC, Bhattacharya N, Shapiro J. The reliability of the assessment of endoscopic laryngeal findings associated with laryngopharyngeal reflux disease. Laryngoscope 2002 Jun;112(6):1019-1024.

13. Dobhan R, Johnston BT, Just RJ, Castell DO. Persistent acid secretion during omeprazole therapy: a study of gastric acid profiles in patients demonstrating failure of omeprazole therapy. Am J Gastroenterol 1996 Aug;91(8):1527-1531.

14. Park W, Hicks DM, Khandwala F, Richter JE, Abelson TI, Milstein C, Vaezi MF. Laryngopharyngeal reflux: prospective cohort study evaluating optimal dose of proton-pump inhibitor therapy and pre-therapy predictors of response. Laryngoscope 2005 Jul;115(7):1230-1238.

15. Bove MJ, Rosen C. Diagnosis and management of laryngopharyngeal reflux disease. Curr Opin Otolaryngol Head Neck Surg 2006 Jun;14(3):116-123.

16. Ratnasingam D, Irvine T, Thompson SK, Watson DI. Laproscopic antireflux surgery in patients with throat symptoms: a word of caution. World J Surg 2011 Feb;35(2):342-348. 